\title{
Study of Maternal and Foetal Complications during Pregnancy
}

\author{
B. R. Abha Ayushree ${ }^{1}$, Anjali Tarai ${ }^{2 *}$, Sunita Kumari ${ }^{1}$ and Usha Singh ${ }^{1}$ \\ ${ }^{1}$ Department of Food and Nutrition, College of Community Science, Dr. Rajendra Prasad \\ Central Agricultural University, Samastipur, Bihar, India \\ ${ }^{2}$ Department of Pharmacology, PRM Medical College, Baripada, Odisha, India \\ *Corresponding author
}

\section{A B S T R A C T}

\section{Keywords}

Complications of pregnancy, Gestational diabetes,

Pregnancy, Pregnancy induced hypertension

Article Info

Accepted: 08 December 2020 Available Online: 10 January 2021
Most pregnancy-related complications appear to resolve at delivery or shortly thereafter. Common examples are nausea, vomiting, gestational diabetes, constipation and pregnancy induced hypertension. Women who developed such complications are known to be at increased risk of developing similar complications in future pregnancies. It has recently become evident that these women are at an increased risk of long-term medical complications affecting both mother and the child health. To study the prevalence of maternal and foetal complications among pregnant women in Bihar. 40 healthy pregnant women of $1^{\text {st }}$ trimester were selected from Harpur panchayat in Pusa, Samastipur, Bihar (India). A specialized questionnaire was developed to record maternal and foetal clinical complications during pregnancy. They were followed up in each month for any pregnancy induced complications. It was found that all women had experienced nausea and vomiting. $60 \%$ had heartburn and $20 \%$ had constipation while $27.5 \%$ suffered from oedema and $32.5 \%$ had anaemia. However, $65 \%$ had cravings and aversion complications. Among foetal complications, $52.5 \%$ had poor growth malformation during pregnancy. It was concluded pregnancy induced complications may increase maternal and foetal death if they were not properly checked. Maximum pregnant women experienced nausea and vomiting during pregnancy. Thus, the prevalence of maternal complication such as nausea and vomiting during pregnancy was highest among the pregnant women.

\section{Introduction}

Pregnancy is an altered physiological and metabolic change in mother because of growing foetus. Therefore there is an altered nutritional requirement. Complications of pregnancy are health problems that are related to pregnancy. It involved the mother's health, the baby's health or both. Sometimes pregnancy complications arise even in healthy women. So the prenatal check up done during pregnancy to spot out the complications early and reduce maternal and foetal mortality and morbidity. Some women have health problems before they become pregnant that could lead to complications like gestational diabetes, anaemia or pregnancy induced hypertension. Other problems arise during the pregnancy, whether complication may be common or rare like nausea, vomiting, 
heartburn, muscle cramps, oedema, constipation or any food cravings and aversion (WHO, 2015) (1). Some complications were observed during early pregnancy while some in the late pregnancy. Due to the complications of pregnancy and childbirth, approximately 303,000 women died in 2015 (WHO, 2015). Clinical symptoms provide the impact regarding the complications during pregnancy. Therefore, clinical examination is an important practical method for assessing the maternal and child health status.

The most common causes of maternal mortality are maternal bleeding, postpartum infections, hypertensive diseases of pregnancy, obstructed labour and pregnancy with abortive outcomes (Kupferminc et al., 1999) (2). Nutritional sufficiency is one of the vital elements before, during and after pregnancy for support of foetal growth, development and maintenance of the mother's body. Due to inadequate intake of nutrients in diet like energy, protein, iron, calcium, etc. leads to various complications like anaemia, megaloblastic anaemia, pregnancy induced hypertension, etc. that affects the birth weight of the offspring (N Burrow, 2004) (3). There is no clear distinction between complications and symptoms of pregnancy. However, the latter do not significantly interfere with daily living activities or pose any significant threat to the health of the mother or baby. Still, in some cases the same basic features can manifest as a complication depending on severity.

For example, mild nausea (morning sickness) may merely be a complication, but if severe vomiting occur causing water-electrolyte imbalance it can be classified as a pregnancy complication (hyperemesis gravidarum, pregnancy induced diabetes mellitus leading to macrosomia baby (Coronado et al., 2000) (4).

\section{Materials and Methods}

For this study, 40 healthy pregnant women of age group 18-25 years at $1^{\text {st }}$ trimester under Harpur panchayat in Pusa block, Samastipur district, Bihar were randomly selected. A specialized questionnaire was developed to record maternal and foetal clinical complications during pregnancy.

They were followed up in each month until delivery for any pregnancy induced complications like anaemia, nausea and vomiting, constipation, heartburn, depression, gestational diabetes, pregnancy induced hypertension, placental abortion, preeclampsia, preterm labour, infection etc. and problems in baby such as poor growth malformation, multiple pregnancies.

\section{Results and Discussion}

The data in Table 1 and Fig. 1 depicted that all the subjects (100\%) commonly experienced nausea and vomiting. This could be due to low energy intake by the subjects. Jarrah et al., (2007) (5) also identified daily symptoms like dizziness, fatigue, depression and headaches. Muscle cramps (15\%) and heart burn $(60 \%)$ were second common symptoms developed in the subjects.

Other clinical complications observed among the subjects were constipation with 20 per cent followed by oedema with 27.5 per cent, cravings and aversion in 65 per cent of subjects. The remaining 13 per cent subjects had major clinical complications like anaemia which was because of less consumption of iron-rich foods by the subjects and only 5 percent subjects had PIH (Pregnancy Induced Hypertension) while 7.5 per cent of the subjects showed GDM (Gestational Diabetes Mellitus). 
Table.1 Prevalence of Maternal Complications $(n=40)$

\begin{tabular}{|c|c|c|}
\hline Complications during Pregnancy & Frequency & Percentage \\
\hline Nausea \& vomiting & 40 & 100.00 \\
\hline Muscle cramps & 6 & 15.00 \\
\hline Heart burn & 24 & 60.00 \\
\hline Constipation & 8 & 20.00 \\
\hline Oedema & 11 & 27.50 \\
\hline PIH (Pregnancy Induced Hypertension) & 2 & 05.00 \\
\hline GDM (Gestational Diabetes Mellitus) & 3 & 07.50 \\
\hline Anaemia & 13 & 32.50 \\
\hline Cravings \& Aversion & 26 & 65.00 \\
\hline
\end{tabular}

Table.2 Foetal Complications during Pregnancy

\begin{tabular}{|l|c|c|}
\hline Foetal Complications & Frequency & Percentage \\
\hline Poor growth Malformation & 21 & 52.50 \\
\hline Miscarriages & 12 & 30.00 \\
\hline Ectopic Pregnancy & 2 & 05.00 \\
\hline Multiple Pregnancies & 1 & 02.50 \\
\hline
\end{tabular}

Fig.1 Prevalence of Maternal Complications among subjects

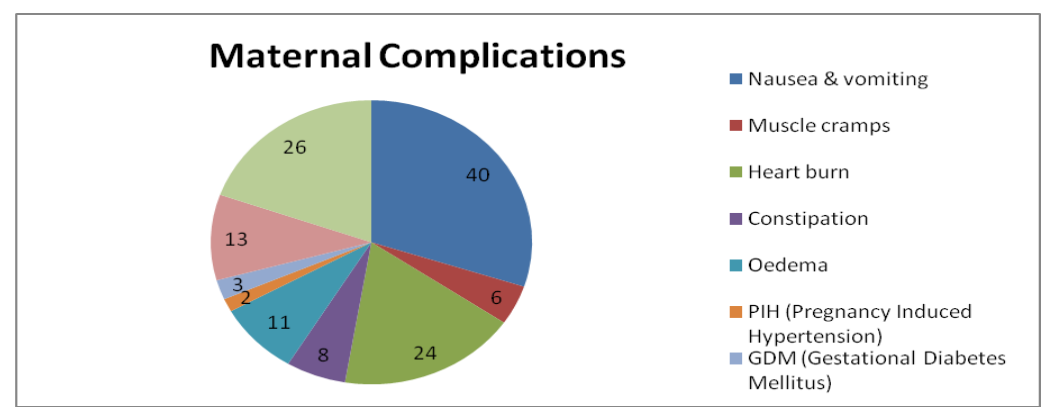

Fig.2 Prevalence of Foetal Complications during Pregnancy

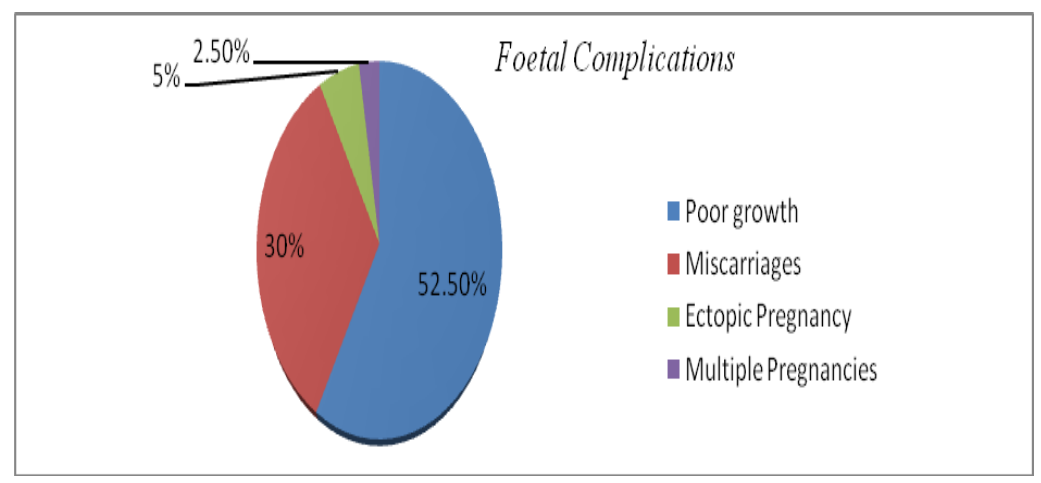


The data in Table 2 and Fig. 2 revealed that majority $(52.5 \%)$ of the pregnant women had poor foetal growth followed by 30 per cent had miscarriages and remaining 5 per cent had ectopic pregnancy while rest 2.5 per cent of the pregnant women had multiple pregnancies. This might be due to poor maternal nutritional status of the pregnant women. Kulshrestha and Agarwal (2016) (6) stated that pregnant women had foetal complications like brachial plexus injury, birth trauma, Intra-Uterine Growth Retardation (IUGR) and congenital malformations during pregnancy.

This study concluded pregnancy induced complications may increase maternal and foetal death if they were not properly checked. Maximum pregnant women experienced nausea and vomiting during pregnancy. So, the prevalence of maternal complication such as nausea and vomiting during pregnancy was highest in the study area. Foetal complication like poor growth malformation was maximum among the pregnant women. Thus, the antenatal and postnatal check up with both dietary and medicinal treatment, follow up give a healthier mother and baby.

\section{References}

1. WHO (2015) Trends in Maternal Mortality: 1990 to 2015-Estimates by
WHO, UNFPA, The World Bank and the United Nations Population Division. Geneva: WHO.

2. Kupferminc, M. J., Eldor, A., Steinman, N., Many, A., Bar-Am, A., Jaffa, A., \& Lessing, J. B. (1999). Increased frequency of genetic thrombophilia in women with complications of pregnancy. New England Journal of Medicine. 340(1): 9-13.DOI: 10.1056/NEJM199901073400102.

3. N Burrow, G. (2004). Medical complications during pregnancy. United States of America.

4. Coronado, G. D., Marshall, L. M., \& Schwartz, S. M. (2000). Complications in pregnancy, labor, and delivery with uterine leiomyomas: a population-based study. Obstetrics \&Gynecology. 95(5): 764-769.https://doi.org/10.1016/S00297844(99)00605-5.

5. Jarrah, S.S., Halabi, J.O., Bond, A.E. and Abegglen, J. (2007). Iron deficiency anaemia (IDA) perceptions and dietary iron intake among young women and pregnant women in Jordan. Journal of Transcultural Nursing. 18: 19-27. https://doi.org/10.1177\%2F104365960629 4193

6. Kulshrestha, V., \& Agarwal, N. (2016). Third Trimester foetal complications in pregnancy with diabetes. Journal of Pakistan Medicine Association. 66(9 Suppl 1): 81-4.

\section{How to cite this article:}

Abha Ayushree, B. R., Anjali Tarai, Sunita Kumari and Usha Singh. 2021. Study of Maternal and Foetal Complications during Pregnancy. Int.J.Curr.Microbiol.App.Sci. 10(01): 628-631. doi: https://doi.org/10.20546/ijcmas.2021.1001.076 